\title{
La religiositat femenina en època moderna
}

\author{
Femenine religiosity in Modern Age
}

\author{
Rosa Maria Alabrús \\ ralabrusi@uao.es
}

Universitat Abat Oliba - CEU

El conjunt d'articles que aquí es presenten és el fruit del Col loqui Internacional Religiosidad femenina en la época moderna. Vidas ejemplares y discurso eclesiástico que va ser dut a terme a la Universitat Abat Oliba-CEU, de Barcelona, els dies 28 i 29 d'abril de 2016. Aquest Col loqui forma part de les activitats culturals desenvolupades en el marc del projecte de recerca $\mathrm{I}+\mathrm{D}+\mathrm{i}$ que porta per títol «La religiosidad femenina en la Cataluña de la época moderna», concedit pel MINECO, del qual sóc investigadora principal, pel període 2015-2018. L'esdeveniment va comptar amb la presència de destacats especialistes i un bon nombre d'assistents, amb una intensa participació en els debats. Voldria subratllar la presència de Jesús Díaz Sariego, provincial de la Província d'Hispània dels Dominics, doctor en Teologia per Friburg, professor de la Facultat de Teologia de València i reconegut especialista en l'obra de Paul Ricqueur. Al llarg de les jornades es va plantejar la problemàtica de la religiositat femenina, durant l'època moderna, amb un enfocament pluridisciplinar que inclou la història, la literatura i l'antropologia.

El Col loqui va incidir, fonamentalment, en dues línies temàtiques que queden reflectides en els articles aquí editats. La primera és la de l'estudi de les vides i les obres de les dones religioses (monges i beates) de l'època moderna, a partir dels seus escrits i dels relats autobiogràfics, la 
influència en els mateixos dels seus confessors i d'altres narradors posteriors. Cal diferenciar el que hi va haver, en aquests manuscrits, d'espontaneïtat, de creació literària, d'imposició o d'afany de discerniment espiritual, determinant els arquetipus d'exemplaritat religiosa, el seguiment o no del model de l'autobiografia teresiana i la seva evolució en el decurs del temps, de les expressions, pel que fa a la religiositat femenina. Els relats biogràfics o autobiogràfics constitueixen una font extraordinària, no només per a conèixer la vida d'aquestes religioses, sinó per a penetrar en la funció de la narrativa i la construcció del model de santedat.

La segona línia temàtica és la de l'anàlisi del discurs eclesiàstic sobre la religiositat femenina: la valoració de l'ascètica i la mística en totes les seves manifestacions (mortificacions, visions, capacitat de profecia...) i llur projecció pública, amb el seu llegat cultural i fundacional. Aquesta vessant pretén enregistrar l'evolució de les actituds que la religiositat femenina suscità des de la vida i l'obra de santa Teresa, amb èmfasi per les fluctuacions constatades, entre els tractadistes eclesiàstics, tant de sublimació màxima de les experiències religioses femenines com de recel i desconfiança cap a l'excés de càrrega emocional d'aquesta espiritualitat.

A l'àmbit de la primera de les línies temàtiques apuntades, s'insereixen, en aquest monogràfic, set articles, que hem ordenat, cronològicament, en funció de l'època analitzada, i que passem a comentar breument, tot seguit.

$\mathrm{M}^{\mathrm{a}}$ del Mar Cortés, professora de la Facultat de Filologia de la Universitat de Barcelona, estudia, en el seu text, la personalitat de Teresa de Cartagena, la qual va escriure, al voltant de 1475, dos tractats (Arboleda de los enfermos i Admiraçion Operum Dey) que constitueixen l'avantguarda de la literatura religiosa castellana del segles XVI, autèntic precedent de l'obra de Teresa de Jesús. De família jueva conversa, professà en el convent de Santa Clara de Burgos. L'exercici d'humilitat, la ironia a l'hora de referir-se a l'escriptura femenina, el fet de blasmar les capacitats intel lectuals de les dones, mitjançant subtils observacions sobre les funcions de gènere, amb la contraposició lletres/armes i la defensa del «derecho a verbalizar las vivencias en femenino del amor divino que las vinculaba directamente a lo absoluto sin mediaciones masculinas», palesen moltes similituds amb la santa d’Àvila.

Michel Boeglin, professor de llengua espanyola a la Université Paul Valéry de Montpeller, amb un important bagatge de publicacions sobre la Inquisició, aborda l'estudi de les dones processades, per luteranisme, en el Tribunal Inquisitorial de Sevilla. En concret, examina els actes de fe executats entre 1559 i 1565 en aquesta ciutat. Del total de cent vint i nou processats a Sevilla, en aquest període, quaranta-un van ser dones (un 31,8 \%), amb un total de condemnes a mort de trentavuit persones, de les quals, catorze van ser-ne dones (un 36,8 \%). L'article planteja les identitats d'algunes d'elles, com la beata María de Bohorques i María de Birués, i destaca, del convent de Santa Paula, un interessant personatge, Leonor de San Cristóbal, i, del convent de Santa Isabel, la monja Francisca de Chaves. 
Ana Morte, professora de la Universidad de Zaragoza, biògrafa de sor María de Àgreda, incideix, a partir de dues dominiques aragoneses, Martina de los Ángeles i Josefa Berride, en el procés d'adquisició de fama de santedat d'algunes dones, en la transició del segles XVI al XVII. Tenint en compte que aquestes esmentades monges no van arribar a escriure cap text, ni van tenir relacions amb membres rellevants de la societat de l'època, la promoció cap a la santedat es va fonamentar només en els presumptes prodigis: en el cas de Martina, a partir de la vinculació amb la tradició de curacions, especialment les produïdes a partir de creus i comptes de rosari beneïts; en el cas de Josefa Berride, amb la fundació d'un beateri que acabaria derivant en un col legi.

Verònica Zaragoza, professora de la Universitat Oberta de Catalunya, aporta filològicament tres poemes inèdits d'Hipòlita de Rocabertí, inclosos en el seu Tratado dividido en quatro litros, editat a València, el 1683, la qual cosa permet conèixer el perfil de poetessa d'aquesta dominica catalana i el procediment de censura i control dels seus poemes, abans de la seva entrada a la impremta. Hi va haver, com diu l'autora, un «previo acomodamiento e intervención por parte de los editores para con los poemas autógrafos antes de la publicación póstuma».

Emilio Callado, professor titular i agregat de la Universidat CEU-Cardenal Herrera, de València, és autor d'una dilatada obra. En el seu article rescata de l'oblit un dels convents femenins dominics més desconeguts de l'àmbit valencià: el del Corpus Christi de Carcaixent. Un dels seus primers confessors va ser José Agramunt que va escriure una història conventual titulada Parayso de Dios. Idea del religiosíssimo monasterio de señoras dominicas de la real villa de Carcaxente, finalitzada el 1701. El llibre es una col lecció de biografies de disset monges, de la segona meitat del segle XVII. Cadascuna d'aquetes es vincula amb una flor. Les monges tractades amb major relleu són Agustina de Nicolás i Hermenegilda de San Bernardo.

Cristina Gimeno-Maldonado, doctoranda de la Universitat Autònoma de Barcelona, analitza en el seu estudi l'obra del carmelita aragonès Roque Alberto Faci, publicada l'any 1743, on hi figuren diverses vides de terciàries carmelitanes (un total de vint i dues), basades en fonts diverses: cròniques locals o de l'ordre carmelitana, etc. Els personatges femenins biografiats més significatius, són donzelles que no arriben a professar, com Paula Villafranca, Isabel Cortés, Ángela de Arena, Rosa $\mathrm{M}^{\mathrm{a}}$ Serio (aquesta va ser biografiada pel jesuïta Gentili); dones casades, com Juana Maria de Quintas; visionàries singulars, com Isabel de Jesús o Luisa Zaragoza... A l'obra de Faci es percep una certa prevenció cap a la Il lustració emergent, amb la mirada posada en la nostàlgia del Siglo de Oro.

Inmaculada Fernández-Arrillaga, professora titular d'Història Moderna de la Universitat d'Alacant, és una reconeguda experta sobre l'expulsió dels jesuïtes en el segle XVIII. Estudia aquí la figura de la beata argentina Maria Antonia de San José, l’anomenada Mamá Antula, nascuda el 1730 i morta el 1799. Aquesta religiosa oferia un gran recolzament als jesuïtes expulsats (en especial al pare Gaspar Juárez), per tal de difondre la pràctica dels exercicis espirituals. Vestida amb l'hàbit de la Companyia, exercí un rol de dona forta, activa i plenament compromesa amb la tasca de salvaguardar la imatge dels jesuïtes. 
Els darrers quatre articles del monogràfic, versen sobre el discurs eclesiàstic al voltant de les expressions de la religiositat femenina.

Francisco Pons Fuster, professor de la Universitat de València, és pioner en els estudis sobre la problemàtica de les beates i dels «il luminats», amb la seves publicacions sobre la València del segle XVI. En el seu article queda clar el desig, per part de l'Església, de construir un model de dona espiritual, la qual cosa es percep a través de l'obra del franciscà Antonio Panes, amb quatre biografies de dones poc conegudes però ben significatives en aquest sentit: Inés Castaño, Juana Godoya, María García González i Ginesa de la Rosa. Les biografies, segons l'autor, tenen caràcter exemplificador i busquen l'aprovació de la jerarquia eclesiàstica en el camí cap a la santedat. Igualment, aquestes vides de religioses van seguir un patró o arquetipus que es perllongaria fins al segle XVIII i principis del segle XIX.

Per la meva part, com a professora titular i agregada de la Universitat Abat Oliba-CEU, després d'estudiar la religiositat femenina a partir de figures tant rellevants com Teresa de Jesús i Hipòlita de Rocabertí, he pretès aportar, en aquest monogràfic, un estudi comparatiu de tres grans tractadistes eclesiàstics, en relació al món visionari en els segles XVI i XVII: un castellà (l'ardiaca de Segòvia Juan de Horozco), un mallorquí (el franciscà Geronimo Planas ) i un català, l'empordanès Antoni de Sant Maties Carbó. En el text es posa en evidència que la desconfiança cap a la religiositat femenina estava ja instal.lada a l'època de Teresa de Jesús. No obstant que ella va poder sortejar els obstacles, en funció de la seva capacitat d'equilibri i autocontrol emocional, la generació posterior viuria l'impacte de la Contrareforma i les manifestacions més radicals de l'espiritualitat femenina. L'obra de Sant Maties Carbó va fer patent la necessitat de conjugar l'admiració per la santa d'Àvila amb les prevencions que la religiositat femenina suscitava, tot i que, al mateix temps, demostrà una actitud tolerant cap a l'espiritualitat de les monges barcelonines a les quals confessava.

Alfonso Esponera Cerdán, catedràtic d'Història de l'Església a la Facultat de Teologia de València, i Pilar Sastre, doctoranda de la Universitat de les Illes Balears, analitzen el debat suscitat per la defensa d'unes «conclusions literàries» teològiques, dedicades a la beata dominica Llúcia de Narni, el 1738 a Mallorca. El fullet de publicitat de l'acte portava una làmina de la beata en la qual es veien els seus estigmes. La Inquisició, davant d'una denúncia dels franciscans observants, manà que es suspengués aquest acte acadèmic. Els dominics van recórrer a Madrid i a Roma. El text reflecteix la confrontació entre franciscans i dominics i les actituds ben diferents respecte a algunes expressions de la religiositat femenina, com el fenomen de les plagues.

Alejandro López Ribao és investigador de l'Instituto Histórico de la Provincia Dominicana de Aragón i doctorand de la Universitat Autònoma de Barcelona. En el seu article examina les onze exhortacions de fra Josep Mercader (un català nascut a Reus que professà l'any 1720), entre 1740 i 1745, dirigides a les monges dominiques del monestir barceloní de Montesión, amb motiu de les cerimònies de recepció i professió. En aquests textos s’inclouen els exempla femenins presentats a les monges. Dones bíbliques, la Verge Maria i santa Teresa de Jesús són esmentades amb freqüència 
com a primers referents de la vida monacal. El major èmfasi, no obstant, es centra en el model de Caterina de Sena, relacionada puntualment amb santa Agnès de Montepulciano.

A la vista dels treballs ara referenciats, el balanç final de resultats que es pot fer dels articles inclosos en aquest recull es centra en tres punts.

En primer lloc, es desvetlla la identitat de moltes religioses absolutament desconegudes fins ara i que van tenir un singular relleu en els seus respectius moments històrics, tal i com palesen les diverses relacions i repertoris de religioses exemplars que s'han recuperat en els articles aquí publicats. Es constata l'ansietat de models referencials i la demanda d'exemplaritat, posada en evidència en les narracions d'aquestes vides o biografies de monges. En aquest monogràfic es demostra que la vocació hagiogràfica del segle XVII, que ja coneixíem bé, es perllongaria en el segle XVIII, el segle de la Il lustració.

En segon lloc, es constata que els camins de les biografies són molt plurals, més enllà de la fita de la santedat permanentment dibuixada. Els relats de les vides evidencien que les monges tenien una diversa procedència social i que en la seva infància $i$ joventut van passar per inclemències múltiples, amb vides difícils, tortuoses, autèntiques carreres d'obstacles. Els relats biogràfics utilitzen referents de vides dispars per elaborar el missatge final d'exemplaritat. Les biografies es construeixen des del final feliç de l'arribada al paradís. La diversitat dels tipus de vida i la unitat del destí final es complementen.

En tercer lloc, els articles manifesten que l'Església no només es va limitar a exhibir les relacions de les seves monges, sinó que, des de finals del segle XVI, entrà en el debat sobre els límits de les expressions de religiositat mística per tal d'intentar controlar els excessos de possible il luminisme. En aquest sentit, els tractadistes no acabaren de consensuar les fronteres de la realitat i l'imaginari, la raó i les emocions, l'activisme voluntarista i el quietisme passiu o contemplatiu, més enllà de remetre's al que l'autoritat eclesiàstica dictés a cada moment. Es veu com, progressivament, en el segle XVII, va imposant-se un criteri cada cop més racionalista i distant de la hipersensibilitat femenina a l'hora de descriure la unió amb Déu. Els tractadistes estan d'acord en la legitimació del món visionari de Teresa de Jesús, però, al mateix temps, és patent que el model teresià és difícilment repetible, per les excepcionals capacitats de la monja d'Àvila per a salvaguardar els equilibris sensitius i intel lectuals. La prevenció i la desconfiança es van fent presents, per temor que l'espiritualitat femenina es pogués projectar cap a ports sense control. Es va intentar regular-la, mitjançant l'encàrrec de les autobiografies, el control dels seus escrits i l'excessiva mortificació. La gestió de les emocions es va convertir en l'objectiu principal de les autoritats eclesiàstiques.

En el capítol final d'agraïments, vull fer constar el recolzament i l'ajut permanent dels diversos membres dels equips de recerca amb els quals el meu projecte va coordinat i dels quals són investigadors principals José Luis Betrán (Universitat Autònoma de Barcelona), Doris Moreno (Universitat Autònoma de Barcelona), Eliseo Serrano (Universidad de Zaragoza), Ángela Atienza 
(Universidad de la Rioja) y Manuel Peña (Universidad de Córdoba). També, a tots els col laboradors i participants en el col loqui d'abril del 2016, que fou la matriu d'aquests articles, en especial a $\mathrm{M}^{\mathrm{a}}$ Ángeles Pérez Samper (Universitat de Barcelona) i a Ricardo García Cárcel (Universitat Autònoma de Barcelona. )

Per últim, vull subratllar el meu agraïment a la revista Scripta i al seu director Vicent Josep Escartí, que ens ha ofert les pàgines la publicació que dirigeix per a fer públics els resultats d'aquesta recerca col lectiva sobre la religiositat femenina. Confio que les aportacions dels autors d'aquests textos puguin ser útils de cara a futures investigacions. 